\title{
Minimal Invasive Techniques for Implant Dentistry: A Review
}

Dr. Navneet Kaur ${ }^{1 *}$, Dr. Kala Bagavathy ${ }^{2}$, Dr. Sankara Rao Sanaka ${ }^{3}$, Dr. Rishabh Bhanot ${ }^{4}$, Dr. Anas Abdul Khader ${ }^{5}$, Dr. V K Sasank Kuntamukkula ${ }^{6}$

${ }^{1}$ Reader, Department of oral and maxillofacial surgery, Guru Nanak Dev Dental College \& RI, Sunam, Punjab, India

${ }^{2}$ Consultant Oral \& Maxillofacial Surgeon, Gokulam Hospital, Nagercoil, India

${ }^{3} 3$ rd year Post graduate student, Department of Oral and maxillofacial surgery, M.N.R.Dental College, Sangareddy, Telangana, India

${ }^{4}$ Consultant Oral and Maxillofacial surgeon, SRCJC hospital, Ludhiana India

${ }^{5}$ Associate professor, Department of Periodontology, Azeezia Dental College, Quilon, Kerala India

${ }^{6} \mathrm{MDS}$, Assistant Professor, Department of Oral and Maxillofacial Surgery, Sri Sai College of Dental Surgery, Vikarabad, India

DOI: $10.36348 /$ sjodr.2019.v04i11.004 $\quad$ | Received: 02.11.2019| Accepted: 18.11.2019 | Published: 25.11 .2019

*Corresponding author: Dr. Navneet Kaur

\section{Abstract}

The placement of dental implants is becoming a routinely performed procedure in dental practice. Numerous techniques have been advocated to facilitate the placement of dental implants in a wide range of clinical scenarios. However, they are associated with their own share of patient related complications and discomfort. This article throws light on the various minimal invasive techniques available to facilitate implant placement with minimal complications and maximum patient acceptance.

Keywords: Dental implants Techniques. Copyright @ 2019: This is an open-access article distributed under the terms of the Creative Commons Attribution license which permits unrestricted
use, distribution, and reproduction in any medium for non-commercial use (NonCommercial, or CC-BY-NC) provided the original author and source
are credited.

\section{INTRODUCTION}

Dental implants were proven to be the treatment of choice for the replacement of the missing dentition. The success of an implant is governed by its primary stability which is greatly influenced by the amount of residual bone volume available.

A conventional approach to dental implant surgery comprises of a crestal incision and reflection of mucoperiosteal flap to gain access to the underlying alveolar bone. It also allows the identification and protection of underlying anatomical structures such as foramina, lingual undercuts, and maxillary sinuses. In clinical scenarios where there is inadequate residual alveolar bone, flap reflection will facilitate implant placement by optimizing implant positioning and minimizing the risk of bone fenestrations [1].

In current scenarios, the clinician as well as the patient prefers a minimally invasive surgical approach for the implant placement. Hence, this article reviews the various minimal invasive techniques available for implant placement.

\section{Transgingival implant therapy}

It is a minimal invasive technique for implant placement which involves a flapless implant surgery wherein a surgical procedure is performed to prepare the implant osteotomy and to place the implant without elevation of a mucoperiosteal flap [2, 3]. This approach is considered to significantly reduce the operating time, postoperative bleeding, patient discomfort, thereby increasing the patient acceptance [4]. It also helps in the preservation of vascularity, soft-tissue architecture, hard tissue volume, and accelerated recovery. This allows the patient to resume normal oral hygiene measures immediately after the procedure [2].

For immediate implant placement in fresh extraction socket, this technique is preferred to preserve vascular supply and existing soft-tissue contours, thereby optimizing the healing of peri-implant tissues [5]. Since it is a blind surgical procedure, it is associated with certain surgical risks and complications. It includes the increased risk of damage to vital structures like the underlying nerves or adjacent tooth. However, with the aid of computer-guided navigation these drawbacks can be nullified [6].

Based on the existing literature it can be concluded that although the flapless technique is proven to be more beneficial when combined with CAD-CAM technique, but due to its cost sensitivity and complexity, other methods of placing flapless implants without a surgical guide, should be considered. 


\section{Minimally invasive maxillary sinus elevation using} balloon system

A loss in the vertical residual bone height in the posterior edentulous maxilla may be attributed to the postextraction ridge atrophy in addition to the pneumatization of the maxillary sinus, thus restraining the placement of dental implants. Maxillary sinus augmentation has been considered as the most common surgical intervention in such clinical scenarios. It involves the detachment of schneiderian membrane from the maxillary sinus floor to create a space filled with bone graft to promote vertical bone augmentation into the maxillary sinus cavity which enables the restoration with dental implants [7].

Boyne and James proposed the conventional sinus augmentation procedure of direct visualization and manipulation of the schneiderian membrane, through the lateral window osteotomy [8]. Shorter implants were considered as an alternative to sinus lift procedures. However, they were associated with high failure rates when compared to longer implants [9].

Minimally invasive antral membrane balloon elevation is a surgical technique developed as a less invasive alternative to lateral window approach. It involves a crestal approach followed by the sinus elevation using the sinus balloon system. Literature review reveals that this technique offers predictable results and it is safe and effective. It also eliminated the complications associated with conventional lateral window technique [10]. This procedure can be performed with simultaneous implant placement or to develop a site for future implant placement depending on the presence of bone height beneath the sinus floor.

Irradiated cancellous bone allograft exhibits porosity, permitting cell migration, tissue in-growth, fluid exchange, and vascularization. Hence, a study advocates the use of these grafts to ensure volume maintenance and permit new bone formation to achieve osseointegration after implant placement [7].

\section{One piece implants}

Conventional implant systems have some limitations in restoring certain edentulous spaces due to few anatomical restrictions. One of such clinical situation may be no availability of sufficient space between adjacent edentulous teeth for the use of a conventional implant. One-piece implants assist in restoring edentulous spaces that previously could not be restored with conventional implants. They also encourage the use of minimally invasive surgical techniques which encourage maximum tissue preservation [11].

One-Piece implant presents a unique monobloc design that integrates both implant and superstructure which facilitates a simple and swift one-stage procedure. Implants are specifically designed for use in narrow ridges and tight spaces [12]. They are less time consuming as they eliminate the need for second stage surgery. This reduces the patient discomfort. The advanced surface morphology of the implant offers a high initial stability [13]. They are less invasive and can be immediately loaded in clinical situations where there is good bone quality.

\section{Minimally invasive flapless versus flapped approach for single implant placement}

The flapless technique is performed with the aid of a rotary burs or a tissue punch to gain access to the bone without flap elevation. This facilitates the preservation of the vascular supply and surrounding soft tissue. Less surgical trauma with short operative time leading to rapid post-surgical healing and fewer postsurgical complications in addition to decreased patient discomfort are considered to be the main strengths of this technique $[14,15]$.

In addition to this, it is considered that when implants were placed without flap reflection, the length of the junctional epithelium is extended more coronal than in flap surgery, which may provide an environment that is less prone to peri-implantitis[16]. It can be advocated that the inflammation that occurs during the first 3 weeks of healing plays a crucial role in early peri-implant bone loss [16]. Hence, early bone loss can be prevented or minimized if soft tissue wound around the dental implants heals quickly with little inflammation and scar tissue formation [17].

Conventional flapless implant surgery with the aid of a soft tissue punch device necessitates a circumferential excision of keratinized tissue at the implant site. This avoids the preservation of the periimplant keratinized mucosa. Although the importance of keratinized mucosa around implants is deliberated, reduced keratinized mucosa around implants appears to be associated with inflammation and poor oral hygiene [18].

A drawback with this technique is that the true topography of the underlying available residual bone cannot be observed because the mucogingival tissues are not elevated. Furthermore, this approach is only indicated when the surgeon has planned the procedure in such a way that the underlying osseous anatomy is ideal relative to the planned implant diameter and three dimensional placement in the alveolus. Typically, this is determined by clinical and radiographic evaluation aided by analysis of articulated dental study models. Another prerequisite for the use of this technique is the determination of whether a sufficient volume of good quality soft tissues will persist surrounding the emerging implant structures to fulfill biologic width requirements thereby promoting optimal long term function and esthetics. 


\section{REFERENCES}

1. Yadav, M. K., Verma, U. P., Parikh, H., \& Dixit, M. (2018). Minimally invasive transgingival implant therapy: A literature review. National journal of maxillofacial surgery, 9(2), 117.

2. Sclar, A. G. (2007). Guidelines for flapless surgery. Journal of oral and maxillofacial surgery, 65(7), 20-32.

3. Brodala, N. (2009). Flapless surgery and its effect on dental implant outcomes. International Journal of Oral \& Maxillofacial Implants, 24.

4. Arısan, V., Karabuda, C. Z., \& Özdemir, T. (2010). Implant surgery using bone-and mucosa-supported stereolithographic guides in totally edentulous jaws: surgical and post-operative outcomes of computer-aided vs. standard techniques. Clinical oral implants research, 21(9), 980-988.

5. Rocci, A., Martignoni, M., \& Gottlow, J. (2003). Immediate loading of Brånemark System ${ }^{\circledR}$ TiUnite $^{\mathrm{TM}}$ and machined-surface implants in the posterior mandible: a randomized open-ended clinical trial. Clinical Implant Dentistry and Related Research, 5, 57-63.

6. Sießegger, M., Schneider, B. T., Mischkowski, R. A., Lazar, F., Krug, B., Klesper, B., \& Zöller, J. E. (2001). Use of an image-guided navigation system in dental implant surgery in anatomically complex operation sites. Journal of Cranio-Maxillofacial Surgery, 29(5), 276-281.

7. Dhandapani, R. B., Baskaran, S., Arun, K. V., \& Kumar, T. S. S. (2016). Minimally invasive maxillary sinus elevation using balloon system: A case series. Journal of Indian Society of Periodontology, 20(4), 468.

8. BOYNE, P. J. (1980). Grafting of the maxillary sinus floor with autogenous marrow and bone. $J$. Oral Surg., 38, 613-616.

9. Esposito, M., Pistilli, R., Barausse, C., \& Felice, P. (2014). Three-year results from a randomised controlled trial comparing prostheses supported by 5 -mm long implants or by longer implants in augmented bone in posterior atrophic edentulous jaws. Eur J Oral Implantol, 7(4), 383-95.

10. Kfir, E., Kfir, V., Eliav, E., \& Kaluski, E. (2007). Minimally invasive antral membrane balloon elevation: report of 36 procedures. Journal of periodontology, 78(10), 2032-2035.
11. Lauritano, D., Grassi, R., Di Stasio, D., Lucchese, A., \& Petruzzi, M. (2014). Successful mandible rehabilitation of lower incisors with one-piece implants. Journal of medical case reports, 8(1), 406.

12. Wu, A. Y. J., Hsu, J. T., Chee, W., Lin, Y. T., Fuh, L. J., \& Huang, H. L. (2016). Biomechanical evaluation of one-piece and two-piece smalldiameter dental implants: In-vitro experimental and three-dimensional finite element analyses. Journal of the Formosan Medical Association, 115(9), 794800.

13. Rajput, N., Siyad, K. P., Rathinavelu, G., Chandrasekaran, S. C., \& Mohammed, J. (2013). Minimally invasive transmucosal insertion and immediate provisonalization of one-piece implant in partially edentulous posterior mandible. Journal of clinical and diagnostic research: JCDR, 7(9), 2070.

14. Casap, N., Tarazi, E., Wexler, A., Sonnenfeld, U., \& Lustmann, J. (2005). Intraoperative computerized navigation for flapless implant surgery and immediate loading in the edentulous mandible. International Journal of Oral \& Maxillofacial Implants, 20(1).

15. Oh, T. J., Shotwell, J., Billy, E., Byun, H. Y., \& Wang, H. L. (2007). Flapless implant surgery in the esthetic region: advantages and precautions. International Journal of Periodontics \& Restorative Dentistry, 27(1).

16. You, T. M., Choi, B. H., Li, J., Xuan, F., Jeong, S. M., \& Jang, S. O. (2009). Morphogenesis of the peri-implant mucosa: a comparison between flap and flapless procedures in the canine mandible. Oral Surgery, Oral Medicine, Oral Pathology, Oral Radiology, and Endodontology, 107(1), 66-70.

17. Lee, D. H., Choi, B. H., Jeong, S. M., Xuan, F., Kim, H. R., \& Mo, D. Y. (2010). Effects of soft tissue punch size on the healing of peri-implant tissue in flapless implant surgery. Oral Surgery, Oral Medicine, Oral Pathology, Oral Radiology, and Endodontology, 109(4), 525-530.

18. Gobbato, L., Avila-Ortiz, G., Sohrabi, K., Wang, C. W., \& Karimbux, N. (2013). The effect of keratinized mucosa width on peri-implant health: a systematic review. International Journal of Oral \& Maxillofacial Implants, 28(6). 